\title{
Volatile Components of Boiled and Roasted Short-necked Clam Tapes philippinarum
}

\author{
Tetsuo Kawai, ${ }^{* 1}$ Yuzaburo Ishida, ${ }^{* 2}$ Hirofumi Kakiuchi, ${ }^{* 1}$ \\ Nobuo Ikeda, ${ }^{* 1}$ and Tomoyuki Tsuneya ${ }^{* 1}$ \\ (Received November 6, 1989)
}

\begin{abstract}
The volatile components were experimentally produced by heating short-necked clam (Tapes philippinarum) with glass beads. Three flavor concentrates, obtained by distillation at three temperature ranges $\left(98-101,101-115\right.$, and $115-160^{\circ} \mathrm{C}$ ), were analyzed by GC-MS. A total of 76 compounds were identified. They included 9 acyclic nitrogen compounds, 9 pyrazines, 6 pyridines, 6 pyrroles, 5 pyrrolidines, 5 acyclic sulfur compounds, and 1-methylpyrrolidine-2,5-dione.

The last concentrate $\left(115-160^{\circ} \mathrm{C}\right)$ gave a pleasant roasted odor of short-necked clam was characterized by the following flavor components: $3,4,5,6$-tetrahydro-2, 4, 6-trimethyl- $2 \mathrm{H}-1,3,5$ thiadiazine, 5, 6-dihydro-2, 4, 6-trimethyl- $4 H$-1, 3, 5-dithiazine, 2-methyl-2-thiazoline, 3-hydroxy2-methyl-4H-pyrone (maltol), and $N, N$-dimethylglycine methyl ester. While the second concentrate $\left(101-115^{\circ} \mathrm{C}\right)$ having the boiled odor of the clam contained some pyrazines, some pyridines, and the ester as major flavor components.
\end{abstract}

Short-necked clam (Tapes philippinarum), with a wide range of distribution extending from the Philippine Islands to the Kuril Islands lying in the Sea of Okhotsk, ${ }^{12}$ is a delicacy due to its flavor. It also grows on the coasts of Hawaii, California, and Canada, after being introduced from Japan into those regions. ${ }^{1)}$ It gives an appetizing odor when heated, especially when roasted, although it has merely a weak fishy or marine odor when fresh. However, no literature on capillary gas chromatographic (GC) analysis of heated short-necked clam volatiles is available. Only limited information concerning heated volatiles on short-necked clam and soft-shell clam (Mya arenaria) has been published by Nishibori et al., ${ }^{2)}$ Gadbois et. al., ${ }^{3)}$ and Mendelsohn and Brooke, ${ }^{4)}$ before capillary GC was development. The latter workers have identified more than twenty volatile components from cooked soft-shell clam. Among the components, methylthiomethane was reported to have been the most dominant head gas component and the source of the typical clam odor. ${ }^{4)}$ The compound has been recently recognized as a mutually common volatile in bivalves ${ }^{5\rangle}$ including shortnecked clam and in unicellular algae, ${ }^{6,7)}$ so that there must be the food-chain. ${ }^{7>}$ Much information on volatiles of bivalves has been confined to volatiles arising from raw or during storage..$^{3,4,8, \theta)}$ Josephson et al. ${ }^{10)}$ have revealed characteristic flavor components of fresh Pacific oyster by using capillary GC. Yasuhara ${ }^{11}$ ) has recently reported a comparison of volatiles between fresh and rotten mussel.

This paper reports on the volatile compounds produced by heating short-necked clam. We also describe comparisons among the constitution of volatile components generated in the three temperature ranges of $98-101,101-115$, and $115-160^{\circ} \mathrm{C}$.

\section{Materials and Methods}

\section{Sample Preparation}

Live short-necked clams Tapes philippinarum, wrapped with plastic sheets on which a catching place (Tokushima, Japan) was printed, were purchased from a local supermarket in February. Their bodies, along with the juice $(426 \mathrm{~g})$, was obtained by hand-shucking from nearly $1 \mathrm{~kg}$ of the clams with shells. They were placed into a $2 l$ round-bottom four-neck flask containing $880 \mathrm{~g}$ of dried glass beads $(2.3 \mathrm{~mm}$, i. d.). The flask was heated with an electric mantle heater with

*1 Laboratory of Flavor Substances, Shiono Koryo Kaisha, Ltd., Niitakakita, Yodogawaku, Osaka 532, Japan (川合哲夫, 垣内博文, 池田信夫, 恒屋知之: 塩野香料(株)).

*2 Laboratory of Microbiology, Department of Fisheries, Faculty of Agriculture, Kyoto University, Kyoto 606 , Japan (石田祐三郎: 京都大学農学部水産学科). 
moderate stirring. This glass beads method (tentative name) was previously described with the apparatus and the procedures. ${ }^{12, *)}$ The fractions distilled by the three temperature ranges (temperature of the beads) were repeatedly extracted by ether and $\mathrm{CH}_{2} \mathrm{Cl}_{2}$ until their odors disappeared. The extracts evaporated at reduced pressure till approximately 30,90 , and $300 \mathrm{mg}$ of flavor concentrates remained. They were stored at $-20^{\circ} \mathrm{C}$ and then submitted to GC and GC-MS analyses.

\section{Identification of Compounds}

Almost all standard compounds for identification were purchased commercially (Aldrich Chemical Co., Milwaukee; Tokyo Kasei Kogyo, Co., Tokyo; Wako Pure Chemical Co., Tokyo). 3, 4, 5, 6-Tetrahydro-2, 4, 6-trimethyl-2H-1, 3, 5-thiadiazine dihydrate (54, peak No. in Table 2) and 5, 6-dihydro-2, 4, 6-trimethyl-4H-1, 3, 5dithiazine (60, thialdin) were synthesized according to the methods described previously: ${ }^{13)} 54, \mathrm{mp}$. $68.5^{\circ} \mathrm{C}$ (ref. $69.4^{\circ} \mathrm{C}^{13)}$ ), yield $70 \% ; 60,46.8^{\circ} \mathrm{C}$ (ref. $\left.47.3^{\circ} \mathrm{C}^{13)}\right), 95 \%$.

\section{Apparatus for Analysis}

The flavor concentrates were analyzed by capillary gas chromatography (GC) on a HewlettPackard 5840A chromatograph equipped with a non-polar column; $0.25 \mathrm{~mm}$ (i, d. $) \times 30 \mathrm{~m}(0.25$ $\mu \mathrm{m}$ film, DB-1 fused silica). The compounds containing sulfur and nitrogen were also recorded on a gas chromatograph; Hitachi 163 equipped with a flame photometric detector (FPD), flame thermionic detector (FTD), together with a flame ionization detector (FID). Volatile components were identified by capillary gas chromatography-mass spectrometry (GC-MS) analysis on a Hitachi M-80A combined with a $0.25 \mathrm{~mm}$ (i. $\mathrm{d}$.) $\times 50 \mathrm{~m}$ capillary column $(0.25 \mu \mathrm{m}$ film,
DB-1 fused silica). Running conditions on these apparatus were the same as described previously. ${ }^{12}$ Ionization energy was $20 \mathrm{eV}$. For each concentrate, $0.6 \mu \mathrm{l}$ was injected into GC.

\section{Results and Discussion}

\section{Alteration of $\mathrm{pH}$ during Heating}

Table 1 shows thermal effects on distillates generated from the heated short-necked clamglass beads system; the $\mathrm{pH}$ values altered from

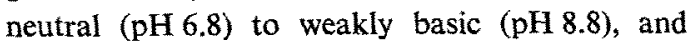
odors of distillates changed from weakly boiled to roasted odors as temperature of the beads elevated.

There is no significant difference in the $\mathrm{pH}$ values on the clam juice (pH 6.8-7.0) between the first distillate ( $\mathrm{pH} 6.8)$ and the second one (pH 7.0). It supports the fact that neither fresh nor boiled short-necked clam contained ammonia as reported by Nishibori et al..$^{2\rangle}$ As compared with these $\mathrm{pH}$ values, the different $\mathrm{pH}$ value (pH 8.8) on the last distillate suggests that thermal interactions on short-necked clam principally occurred above $115^{\circ} \mathrm{C}$.

On the other hand, as previously reported,* the $\mathrm{pH}$ values of distillates obtained from heating dried squid with water $(1: 1)$ in the similar manner as the present test, altered from 9.8 (at $101^{\circ} \mathrm{C}$ ) to 8.6 (at $160^{\circ} \mathrm{C}$ ). In the report, we estimated that large generation of ammonia made the distillates basic.

The two initial $\mathrm{pH}$ values of the clam juice and the extract of dried squid ( $\mathrm{pH} \mathrm{6.8,} \mathrm{dried} \mathrm{squid:}$ water $=1: 9$ ) were exactly the same before heating, but a large gap in the $\mathrm{pH}$ values between their first distillates (pH 6.8 and 9.8) was observed. Therefore, different kinds of volatile constitution must have been formed at higher temperature

Table 1. Alteration of $\mathrm{pH}$ and odors of distillates during heating short-necked clam up to $160^{\circ} \mathrm{C}$

\begin{tabular}{|c|c|c|c|c|c|}
\hline \multirow{2}{*}{$\begin{array}{l}\text { temperature } \\
\text { range }\end{array}$} & \multirow{2}{*}{$\begin{array}{l}\text { temperature } \\
\left({ }^{\circ} \mathrm{C}\right)\end{array}$} & \multirow{2}{*}{$\begin{array}{c}\text { time } \\
(\mathrm{min})\end{array}$} & \multicolumn{2}{|c|}{ distillate } & \multirow{2}{*}{ odor profile } \\
\hline & & & (g) & $\mathrm{pH}$ & \\
\hline & $25 \sim 98$ & 25 & & & \\
\hline $\mathbf{A}$ & $98 \sim 101$ & 65 & 224 & 6.8 & $\begin{array}{l}\text { weakly boiled odor with unpleasant steam } \\
\text { distillation odor }\end{array}$ \\
\hline B & $101 \sim 115$ & 20 & 80 & 7.0 & boiled odor \\
\hline $\mathrm{C}$ & $115 \sim 160$ & 15 & 30 & 8.8 & pleasant roasted odor \\
\hline total & & 125 & 334 & & \\
\hline
\end{tabular}

* T. Kawai, Y. Ishida, H. Kakiuchi, N. Ikeda, and T. Higashida: submitted for publication in $J$. Agric. Food Chem. 


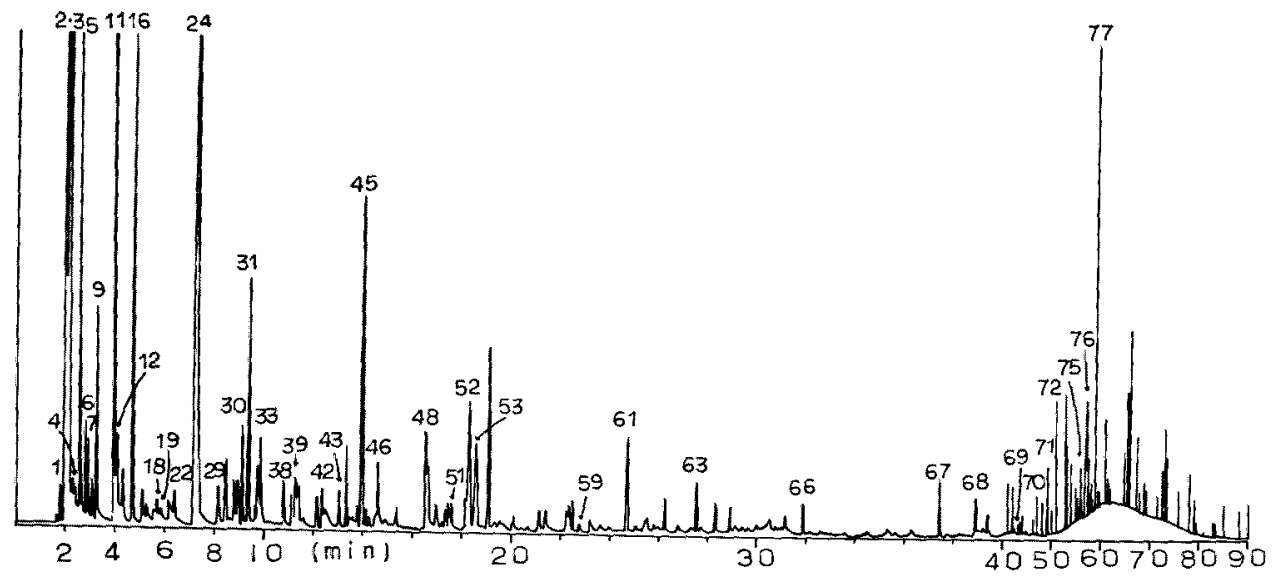

Fig. 1. Gas chromatogram of the volatile concentrate obtained from heated short-necked clam at the temperature range $98-101^{\circ} \mathrm{C}$.

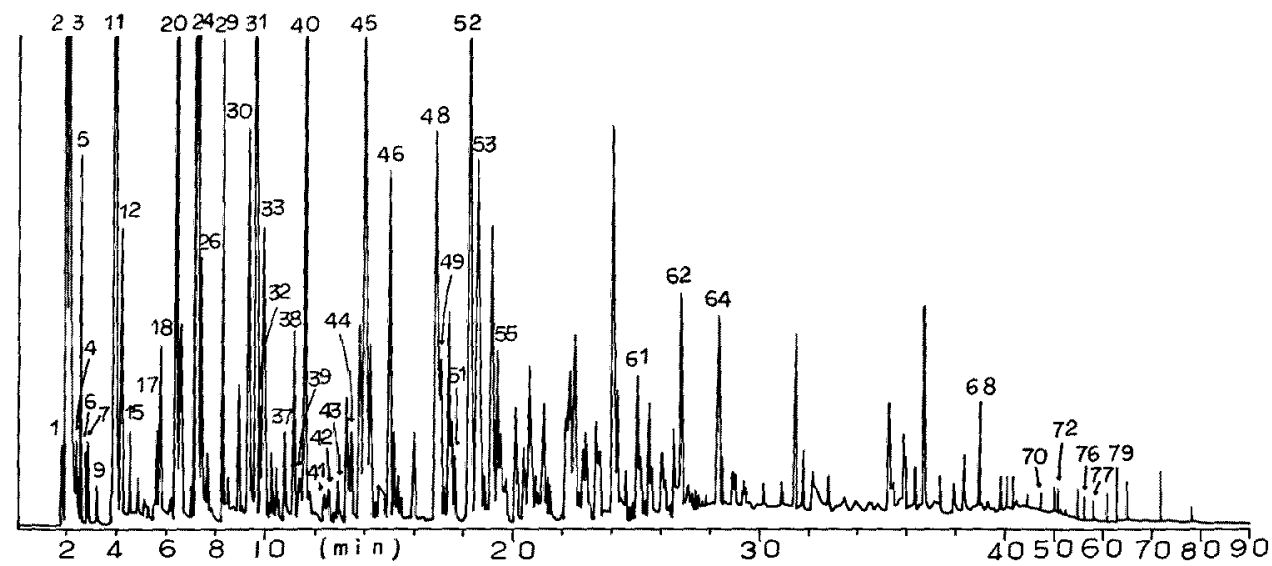

Fig. 2. Gas chromatogram of the volatile concentrate obtained from heated short-necked clam at the temperature range $101-115^{\circ} \mathrm{C}$.

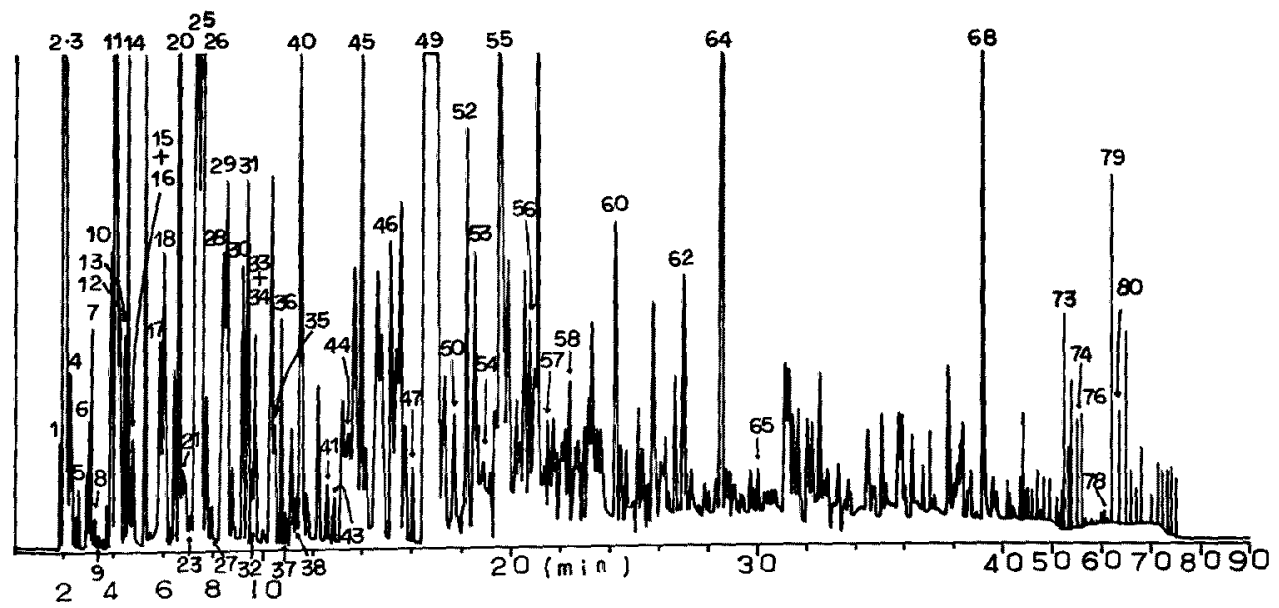

Fig. 3. Gas chromatogram of the volatile concentrate obtained from heated short-necked clam at the temperature range $115-160^{\circ} \mathrm{C}$. 
Table 2. Volatile compounds identified from heated short-necked clam in three temperature ranges $98-101(\mathrm{~A}), 101-115(\mathrm{~B})$, and $115-160(\mathrm{C}){ }^{\circ} \mathrm{C}$

\begin{tabular}{|c|c|c|c|c|c|c|c|}
\hline \multirow{2}{*}{$\begin{array}{l}\text { peak } \\
\text { No. }\end{array}$} & \multirow{2}{*}{ compound } & \multicolumn{2}{|c|}{$\mathrm{KI}(\mathrm{DB}-1)$} & \multicolumn{3}{|c|}{ GC peak area $(\%)$} & \multirow{2}{*}{$\underset{\text { ref }}{\mathrm{MS}, \mathrm{KI}}$} \\
\hline & & unknown & known & $\mathbf{A}$ & B & $\mathbf{C}$ & \\
\hline 1 & ethanal & 472 & 453 & & & & \\
\hline 2 & diethylether (solvent) & & & & & & \\
\hline 3 & dichloromethane (solvent) & & & & & & \\
\hline 4 & 2-butanone & 585 & 560 & 0.09 & 0.10 & 0.05 & \\
\hline 5 & ethyl acetate & 606 & 595 & 2.36 & 0.46 & 0.07 & \\
\hline 6 & 3-methylbutanal & 626 & 628 & 0.15 & 0.10 & 0.10 & \\
\hline 7 & 2-methylbutanal & 637 & 637 & 0.11 & 0.12 & 0.10 & \\
\hline 8 & 1-methylpyrrolidine & 663 & 665 & & & 0.08 & \\
\hline 9 & 3-hydroxy-2-butanone & 670 & 672 & 0.39 & 0.11 & 0.04 & \\
\hline 10 & 2-dimethylaminoethanol & 705 & 708 & & & 0.43 & \\
\hline 11 & pyridine & 715 & 714 & 1.94 & 4.81 & 2.56 & \\
\hline 12 & methyldithiomethane & 724 & 725 & 0.26 & 0.50 & 0.23 & \\
\hline 13 & pyrrole & 727 & 727 & & & 0.39 & \\
\hline 14 & $N, N$-dimethylformamide & 735 & 735 & & & 0.61 & \\
\hline \multirow[t]{2}{*}{15} & 1-ethylpyrrolidine & 750 & (753) & & & & \\
\hline & toluene & 752 & 754 & 1.13 & 0.15 & 0.26 & \\
\hline 17 & 2-methylpyridine & 792 & 796 & & 0.31 & 0.29 & \\
\hline 18 & 2-methylpyrazine & 796 & 798 & 0.08 & 0.52 & 0.43 & \\
\hline 19 & furfural & 800 & 799 & 0.09 & 0.07 & & \\
\hline 20 & $N, N$-dimethylglycine methyl ester & 807 & 810 & & 1.96 & 1.62 & \\
\hline 21 & 2-methylpyrrole & 810 & 812 & & & 0.39 & \\
\hline 22 & 4-hydroxy-4-methyl-2-pentanone & 816 & 815 & 0.11 & & & \\
\hline 23 & 1-(methylthio)-1-ethanethiol & 820 & $(822)$ & & & 0.07 & \\
\hline 24 & 2-furanmethanol & 830 & 830 & 3.62 & 5.70 & & \\
\hline 25 & $N, N$-dimethylacetamide & 832 & 834 & & & 1.87 & \\
\hline 26 & 3-methylpyridine & 832 & 834 & & 0.65 & 1.60 & \\
\hline 27 & dimethylpyrrole & 839 & & & & 0.12 & $\mathrm{MS}^{20)}$ \\
\hline 28 & 2-methyl-2-thiazoline & 847 & 849 & & & 0.30 & \\
\hline 29 & 2-oxolanone & 857 & 859 & 0.27 & 1.02 & 0.53 & \\
\hline 30 & 2-acetylfuran & 877 & 880 & 0.38 & 1.16 & 0.35 & \\
\hline 31 & 2,5-dimethylpyrazine & 881 & 883 & 0.73 & 1.74 & 0.45 & \\
\hline 32 & 2-ethylpyrazine & 888 & 887 & & 0.30 & 0.09 & \\
\hline \multirow[t]{2}{*}{33} & 2,3-dimethylpyrazine & 892 & 895 & 0.48 & 0.95 & & \\
\hline & & & & & & 0.35 & \\
\hline 34 & 2,5-dimethylpyrrole & 897 & 902 & & & & \\
\hline 35 & 2,4-dimethylpyridine & 906 & 908 & & & 0.18 & \\
\hline 36 & $N, N$-dimethylpropionamide* & 911 & 914 & & & 0.30 & \\
\hline 37 & 2,3-dimethylpyridine & 918 & 919 & & 0.70 & 0.11 & \\
\hline 38 & 5-methyl-2-furfural & 925 & 926 & 0.21 & 0.61 & 0.11 & \\
\hline 39 & benzaldehyde & 927 & 931 & 0.19 & 0.17 & & \\
\hline 40 & 3-ethylpyridine & 929 & 932 & & 1.76 & 0.74 & \\
\hline 41 & methyltrithiomethane & 948 & 949 & & 0.20 & 0.28 & \\
\hline 42 & aniline & 950 & 952 & 0.18 & 0.15 & & \\
\hline 43 & phenol & 958 & 961 & 0.13 & 0.18 & 0.18 & \\
\hline 44 & methylethylpyrazine & 969 & & & 0.35 & 0.12 & $\begin{array}{l}\mathrm{MS}^{28)} \\
\mathrm{KI}^{27)}\end{array}$ \\
\hline 45 & 2,3,5-trimethylpyrazine & 973 & 975 & 1.31 & 3.24 & 0.77 & \\
\hline 46 & unknown $(\mathrm{m} / \mathrm{e} 112,41,55,69,84)$ & 990 & & 0.42 & 1.64 & 0.79 & \\
\hline 47 & 1-methylproline methyl ester & 1015 & (1017) & & & 0.20 & \\
\hline 48 & 2-acetylpyrrole & 1021 & 1023 & 0.78 & 2.41 & & \\
\hline 49 & 1-methylpyrrolidine-2,5-dione* & 1039 & 1042 & & 0.60 & 2.88 & \\
\hline 50 & unknown $(\mathrm{m} / \mathrm{e} 43,57,128,85,72)$ & 1041 & & & & 0.37 & \\
\hline
\end{tabular}


Table 2. Continued

\begin{tabular}{|c|c|c|c|c|c|c|c|}
\hline \multirow{2}{*}{$\begin{array}{l}\text { peak } \\
\text { No. }\end{array}$} & \multirow{2}{*}{ compound } & \multicolumn{2}{|c|}{$\mathrm{KI}(\mathrm{DB}-1)$} & \multicolumn{3}{|c|}{ GC peak area $(\%)$} & \multirow{2}{*}{$\underset{\text { ref }}{\mathrm{MS}, \mathrm{KI}}$} \\
\hline & & unknown & known & $\mathbf{A}$ & B & $\mathbf{C}$ & \\
\hline 51 & 2-acetyl-1-methylpyrrole & 1046 & 1045 & 0.12 & 0.29 & & \\
\hline 52 & 2,5-dimethyl-3-ethylpyrazine & 1053 & 1053 & 0.68 & 2.17 & 0.70 & \\
\hline 53 & 2,6-dimethyl-3-ethylpyrzaine & 1059 & 1060 & 0.89 & 2.36 & 0.76 & \\
\hline 54 & $\begin{array}{l}\text { 3,4,5,6-tetrahydro-2,4,6-trimethyl- } \\
2 H-1,3,5 \text {-thiadiazine }\end{array}$ & 1066 & 1066 & & & 0.19 & $\mathrm{MS}^{(2)}$ \\
\hline $\mathbf{5 5}$ & $\begin{array}{l}\text { 3-hydroxy-2-methyl-4H-pyrone } \\
\text { (maltol) }\end{array}$ & 1076 & 1079 & & 0.77 & 1.44 & \\
\hline 56 & 3,5-dimethyl-1,2,4-trithiolane & 1107 & 1109 & & & 0.38 & \\
\hline 57 & 1-acetylpyrrolidine & 1125 & 1128 & & & 0.37 & \\
\hline 58 & 1,1-bis(methylthio)ethane & 1146 & & & & 0.32 & \\
\hline 59 & octanoic acid & 1155 & 1158 & 0.08 & & & \\
\hline 60 & $\begin{array}{l}\text { 5,6-dihydro-2,4,6-trimethyl-4H } \\
\text {-1,3,5-dithiazine }\end{array}$ & 1176 & 1181 & & & 0.77 & $\mathrm{MS}^{12\rangle}$ \\
\hline 61 & benzothiazole & 1191 & 1196 & 0.51 & 0.55 & & \\
\hline 62 & 2-(2-furyl)pyrazine & 1226 & & & 0.96 & 0.46 & $\mathbf{M S}^{28)}$ \\
\hline 63 & nonanoic acid & 1251 & 1255 & 0.32 & & & \\
\hline 64 & indole & 1260 & 1264 & & 0.86 & 0.92 & \\
\hline 65 & 3-(methylethyl)-2,4,5-trithiahexane & 1296 & $(1300)$ & & & 0.30 & \\
\hline 66 & decanoic acid & 1348 & 1349 & 0.36 & & & \\
\hline 67 & 2-tert-butyl-4-methoxyphenol & 1460 & 1461 & 0.69 & & & \\
\hline 68 & 2,6-di-tert-butyl-4-methylphenol & 1496 & 1497 & 0.32 & 0.79 & 1.12 & \\
\hline 69 & diphenylamine & 1590 & 1596 & tr & & & \\
\hline 70 & heptadecane & 1701 & 1700 & 0.36 & 0.13 & & \\
\hline 71 & tetradecanoic acid & 1750 & 1758 & 0.96 & & & \\
\hline 72 & hexadecanal & 1800 & 1803 & 0.89 & 0.11 & & \\
\hline 73 & proline anhydride & 1865 & $(1870)$ & & & 0.47 & \\
\hline 74 & methyl hexadecanoate & 1905 & 1907 & & & 0.37 & \\
\hline 75 & dibutyl phthalate & 1922 & 1922 & 0.52 & & & \\
\hline 76 & hexadecanoic acid & 1974 & 1981 & 1.74 & 0.20 & 0.86 & \\
\hline 77 & octadecanal & 2004 & & 3.54 & 0.22 & & \\
\hline 78 & methyl octadecanoate & 2103 & 2109 & & & 0.11 & \\
\hline 79 & hexadecanamide & 2138 & 2142 & & 0.27 & 0.73 & \\
\hline 80 & $N$-methylhexadecanamide & 2172 & (2178) & & & 0.41 & \\
\hline
\end{tabular}

Compounds not fixed with $\mathrm{KI}$ (Kovats Indices) are considered to be tentatively identified, solely based on MS (mass spectrum) matching. Compounds with parenthesized KI are identified by comparison with the MS and KI data reported in our previous paper." Assignment of compound (77) is based on fragment analysis of hexadecanal. Numbers in italics are the molecular weights of the unidentified compounds.

- Asterisked compounds have not been reported previously as volatiles of food.24)

ranges between the clam and the dried squid, because ammonia is a well-known natural precursor for heated volatile compounds as well as hydrogen sulfide, methanethiol, and low aliphatic aldehydes. ${ }^{14,15)}$ It is very remarkable that both pleasant roasted odors (in Table 1 and in our previous report*) occurred at near $\mathrm{pH} 9$ in nature. The formation of many flavor compounds found from heated food volatiles was reported to have been substantially dependent on $\mathrm{pH}$ on the basis of model reactions ${ }^{18-20)}$ (e.g. the thiadiazine having a strong roasted odor has facilely formed under basic conditions from the mixture of ethanal, ammonia, and $\mathrm{H}_{2} \mathrm{~S}^{(3)}$ ).

\section{Characterization of Flavor Concentrates}

The three flavor concentrates, having the odors as described in Table 1, were obtained from distillation at the three temperature ranges 98-101 (A), 101-115 (B), and 115-160 (C) ${ }^{\circ} \mathrm{C}$, and then analyzed by GC-MS. Their GC chromatograms are shown in Fig. 1-3, respectively. The different GC patterns among those Figures show that the volatile constitution became more complicated as temperature rose. They indicate that interactions among low molecular weight compounds arising from heated short-necked clam obviously increased in the flask. The patterns also reflect the difference among the 
Table 3. Mass spectral data of volatile compounds found in heated short-necked clam

$\begin{array}{ll}\text { 2-methyl-2-thiazoline (28) } & 101\left(\mathrm{M}^{+}, 50\right), 60(100), 59(43), 55(32), 45(30), 42(28) . \\ N, N \text {-dimethylpropionamide (36) } & 101\left(\mathrm{M}^{+}, 58\right), 72(54), 57(31), 45(73), 44(100), 42(6) . \\ \text { 1-methylpyrrolidine-2,5-dione (49) } & 113\left(\mathrm{M}^{+}, 60\right), 85(5), 84(3), 58(12), 57(8), 56(100), 55(6) . \\ \text { 1,1-bis(methylthio)ethane (58) } & 122\left(\mathrm{M}^{+}, 8\right), 75(100), 59(18), 47(21), 41(28) . \\ \text { octadecanal (77) } & 268\left(\mathrm{M}^{+}, 0\right), 250(3), 222(6), 182(6), 96(70), 82(100), 68(70), 57(72) .\end{array}$

odors.

Table 2 lists 76 identified compounds alongside their corresponding GC peak numbers as in those Figures, accompanying their $\mathrm{KI}$ data and GC areas together with MS and KI references. Table 3 compiles MS data of the little known compounds that appear as volatile components of foods.

Methylthiomethane, an easily organoleptical odor associated with marine products, was detected in each distillate and also estimated by the FPD chart. However, its presence based on MS proof was obscure, because of hindrance from covering with peaks of solvents.

The first concentrate possesed 2-furanmethanol (24), octadecanal (77), ethyl acetate (5), and pyridine (11) as major components. Among the identifiable compounds, characteristic impact compounds were lacking in the concentrate. Compounds $(1,4,6$, and 16) have been found from cooked soft-shell clam. ${ }^{3,4}$ )

The second concentrate consisted mainly of the alcohol, the pyridine, some pyrazines (45, 52, and 53), 2-acetylpyrrole (48), $N, N$-dimethylglycine methyl ester (20), and 3-ethylpyridine (40). Compounds $(\mathbf{4 5}, \mathbf{5 2}$, and 40 ) were reported as having the following odors: 45, sweet and caramel $^{21)} ; 52$, nutty and walnuts ${ }^{21} ; \mathbf{4 0}$, buttery, green, and caramel like odors. ${ }^{22)}$ The ester, identified as a volatile of roasted dried squid, has an odor of heated dried squid.*) The odor belongs to a fishy odor. 3-Hydroxy-2-methyl$4 H$-pyrone (55, maltol), well known as giving sweet, caramel, and burnt sugar like odors, occurred in the concentrate. 5-Methyl-2-furfural (38) has sweetish and dusty odors. Consequently, the concentrate was characterized organoleptically by the above dominant but mild-flavor components having sweet, nutty, and other odors, in addition to the ester. The combination of those compounds probably contributes to the boiled odor of short-necked clam.

The last concentrate was composed principally of pyridine (11), 1-methylpyrrolidine-2, 5-dione (49, $N$-methylsuccinimide), $N, N$-dimethylacetamide (25), the ester, 3-methylpyridine (26), and maltol. The pyrrolidine, possessing no odors, was thought to be formed from an intereaction of succinic acid with methylamine or its analogues, because the large content of the acid in shortnecked clam has been determined. ${ }^{29}$ ) The amide has a weak amine like odor. Pyridine (26) was reported to have green, earthy, and hazelnut like odors. ${ }^{29}$ However, the concentrate was much characterized by some impact flavor components; the thiadiazine, the dithiazine, and 2-methyl-2thiazoline (28), together with two considerably large amounts of maltol and the ester.

The thiadiazine has a powerful odor; strong roasted cereal and popcorn like odors which are changeable on $\mathrm{pH}^{13)}$ The compound has been quite recently found from dried squid.*) It is considered an important contributor to roasted odors of marine products on the basis of some blending tests. However, it always appeared as a small peak on GC, and its peak on GC was smaller than that on the MS chromatogram. Its small appearance on $\mathrm{GC}$ is probably due to its instability upon $\mathrm{GC}$ heating along with its high sublimation, ${ }^{13)}$ and the gap is most likely caused by the difference between GC and GC-MS thermal systems where GC heating is more strict than GC-MS heating. Whereas, the thiadiazine has two hydrates for its stable form, ${ }^{13)}$ such as stable hexahydro-2, 4, 6-trimethyl-1, 3, 5-triazine (acetaldehyde ammonia trimer) has three hydrates. The thiadiazine dihydrate has remained nearly unchanged at $-20^{\circ} \mathrm{C}$ over a few years. However, when put into $\mathrm{GC}$, almost all the hydrate must be changed to the unstable anhydride by GC heating; no anhydrous crystals were obtained even at room temperature. ${ }^{13)}$ Its behavior resembles that of the triazine. ${ }^{13)}$ Therefore, the genuine thiadiazine in the last concentrate before submission to $\mathrm{GC}$ analysis is considered to be much larger than that represented by the GC area in Table 2.

The dithiazine was reported to have a roasted shrimp like odor together with other heated food odors. ${ }^{13)}$

Maltol, having a sweet odor as mentioned above, occurred largely in the concentrate. It has been found in many food volatiles from plant origin, with the exception of milk. ${ }^{24)}$ Since short-necked 
clam contains glycogen in abundance as a characteristic chemical property of bivalves, ${ }^{293}$ the present maltol must have formed through nonenzymatic browning reaction from glycogen or glucose. ${ }^{2 n)}$

The thiazoline has been recently identified as a volatile component of heated beef, and it was noted to have a meaty odor. ${ }^{21}$ In addition to the odor, it exhibits an irritant roasted odor with fishy and green odors. Also, as having strong odors, indole (64) and some sulfur compounds $(23,56,58$, and 65$)$ can play significant roles in the roasted odor of short-necked clam. The pleasant roasted odor is probably due to these intense flavor components.

Compounds (46 and 50) remained unidentified. Their MS fragmentation patterns respectively resembled those of 2-hydroxy-3-methyl-2-cyclopenten-1-one and 4-hydroxy-2, 5-dimethyl-3 (2 H)-furanone, but their $\mathrm{KI}$ were inconsistent with authentic ones (KI 1006 and 1031). They seemed to suggest more contributors to sweet and burntsugar odors in the concentrate except maltol. 2, 6-Di-tert-butyl-4-methylphenol (68, BHT) and 2-tert-butyl-4-methoxyphenol (67, BHA) have been frequently detected from volatiles of sea foods wrapped with plastic sheets or packed in such containers (e. g. dried squid and salted cod roe) ${ }^{122}$. The difference in the former GC peak areas depends on its azeotrope.

As described above, higher temperature produced larger amounts of volatiles (in experimental section), more various compounds, and stronger flavor components. Thus, roasting short-necked clam gives more intense, more intricate, more characteristic, and then more favored odors than boiling one.

\section{Acknowledgment}

This work was partially supported by a Grantin-Aid for Scientific Research from the Ministry of Education, Science and Culture, Japan (63860027).

\section{References}

1) T. Habe and K. Ito: in "Shells of the World in Colour, Vol. 1, The Northern Pacific", Hoikusha, Tokyo, 1966, pp. 139.

2) K. Nishibori, S. Kanamitsu, and K. Okamoto: Kaseishi, 23, 27-31 (1972).

3) D. F. Gadbois, J. M. Mendelsohn, and L. J. Ronsivalli: J. Food Sci, 32, 511-515 (1967).
4) J. M. Mendelsohn and R. O. Brooke: Food Tech., 22, 112-116 (1968).

5) H. lida: in "Odor of Marine Products (in Japanese)" (ed. by C. Koizumi), Koseishakoseikaku, Tokyo, 1989, pp. 42-\$2.

6) Y. Ishida and H. Kadota: Nippon Suisan Gakkaishi., 33, 782-787 (1967).

7) Y. Ishida: in "Environmental Influence on Odors of Fish and Shellifish (in Japanese)" (ed. by T. Motohiro), Koseishakoseikaku, Tokyo, 1989, pp. $70-80$.

8) S. Ikeda: in "Advances in Fish Science and Technology" (ed. by J. J. Connel), Fishing New Books, Surrey, England, 1980, pp. 111-124.

9) R. Yoshinaka: in "Microcomponents of Fish and Shellfish (in Japanese)" (ed. by S. Ikeda), Koseishakoseikaku, Tokyo, 1981, pp. 110-142.

10) D. B. Josephson, R. C. Lindsay, and D. A. Stuiber: J. Food Sci., 50, 5-9 (1985).

11) A. Yasuhara: J. Chromatogr. 409, 251-258 (1987).

12) T. Kawai and Y. Ishida: J. Agric. Food Chem., 37, 1026-1031 (1989).

13) T. Kawai, M. Irie, and M. Sakaguchi: J. Agric. Food Chem., 33, 393-397 (1985).

14) M. Boelens, L. M. van der Linde, P. J. de Valois, H. M. van Dort, and H. J. Takken: J. Agric. Food Chem., 22, 1071-1076 (1974).

15) T. Shibamoto and G. F. Russell: J. Agric. Food Chem., 25, 109-112 (1977).

16) L. Schutte and E. B. Koenders: J. Agric. Food Chem., 20, 181-184 (1972).

17) C. K. Shu, M. L. Hagedorn, B. D. Mookherjee, and C. T. Ho: J. Agric. Food Chem., 33, 438442 (1985).

18) C. K. Shu, M. L. Hagedorn, B. D. Mookherjee, and C. T. Ho: J. Agric. Food Chem., 33, 442446 (1985).

19) H. T. Badings, H. Maarse, R. J. C. Kleipool. A. C. Tas, R. Neeter, and M. C. ten Noever de Brauw: Aroma Res., Proc. Int. Symp. 1975, 6373, Chem. Abstr., 86-70388 g (1977).

20) T. Kawai, M. Irie, and M. Sakaguchi: Koryo, 151, 53-61 (1986).

21) G. MacLeod and J. M. Ames: J. Food Sci, 51, 1427-1434 (1986).

22) G. Vernin (translated by T. Matsukura): Koryo, 143, 47-62 (1984).

23) H. Yamanaka: in "Extractive Components of Fish and Shellfish" (in Japanese) (ed. by M. Sakaguchi), Koseishakoseikaku, Tokyo, 1988, pp. 4455.

24) H. Maarse and C.A. Visscher; in "Volatile Compounds in Food, Qualitative Data, Supplement 5", TNO-CIVO Food Analysis Institute, Zeist, The Netherlands, 1988.

25) J. E. Hodge: in "Symposium on Foods: The Chemistry and Physiology of Flavors" (ed. by 
H. W. Schultz, E. A. Day, and L. M. Libbey), Avi, Westport, Connecticut, 1967 (translated by M. Fujimaki and M. Ichioka), Kenpakusha, Tokyo, 1972, pp. $451-478$.

26) F. W. McLafferty and D. B. Strauffer: in "The Wiley/NBS Registry of Mass Spectral Data", John Wiley \& Sons, New York, 1989.
27) R. A. Flath, K. E. Matsumoto, R. G. Binder, R. T. Cunningham, and T. R. Mon: J. Agric. Food Chem., 37, 814-819 (1989).

28) P. Friedel, V, Krample, T. Radford, J. A. Renner, F. W. Stephard, and M. A. Gianturco: $J$. Agric. Food Chem., 19, 530-532 (1971). 